\title{
Sakubitril/valsartan hedef dozun altındaki dozlarda klinik yarar sağlar mı?
}

\author{
Dr. Deniz Elçik, (D) Dr. Abdurrahman Oğuzhan
}

Erciyes Üniversitesi Tıp Fakültesi, Kardiyoloji Anabilim Dalı, Kayseri

Düşük ejeksiyon fraksiyonlu kalp yetersizliği (KY) tedavisinde sakubitril/valsartanın anjiotensin konverting enzim inhibitörü enalaprile göre hastaneye yatışları ve kardiyovasküler ölümü azalttı̆̆ PARADIGM-HF çalışmasında gösterilmiştir. ${ }^{[1]}$ Sonrasında sakubitril/valsartan KY kılavuzundaki yerini almıştır. ${ }^{[2]}$

PARADIGM-HF çalışmasında randomizasyon öncesi, tek kör bir alıştırma (run-in) periyodu bulunmaktadır. Bu periyodda enalapril günde iki kez $10 \mathrm{mg}$ ve sakubitril/valsartan günde iki kez $200 \mathrm{mg}$ dozunu tolere edebilen hastalar belirlenmiştir. Amaç daha önceki çalışmalarda ölümü azalttığ 1 gösterilen enalapril dozuna çıkılabilen hastaları randomizasyona alarak, sakubitril/valsartan ile sağlıklı bir karşılaştırma yapabilmektir. Randomizasyon sonrası enalapril grubunda \%43, sakubitril/valsartan grubunda ise $\% 42$ hastada tolerabilite nedeniyle doz azaltımına gidilmiştir. Hastaların doz açısından bir alıştırma periyoduna tabi tutulduğu da düşünülürse gerçek hayatta bu oranın daha fazla olabileceği aşikardır. Bu tablo klinisyenlerin aklına hedef dozlardan daha düşük dozlarda, sakubitril/valsartanın enalaprile olan üstünlüğünün devam edip etmediği sorusunu getirmektedir.

$\mathrm{Bu}$ sorunun cevabını karşılayacak literatürde tek bir çalışma mevcuttur. Bu çalışma PARADIGM-HF çalışmasının post-hoc analizinden yapılmıştır. ${ }^{[3]}$ Tolerabilite nedeniyle ilaç dozunun azaltıldı $\breve{g}_{1}$ hastalar değerlendirilmiştir. Rutin dozlar dişında iki ek gurup daha oluşturulmuştur. Birinci grup günde iki kez 100 mg sakubitril/valsartan veya günde iki kez 5 mg enalapril, ikinci grup ise günde iki kez $50 \mathrm{mg}$ sakubitril/ valsartan veya günde iki kez $2.5 \mathrm{mg}$ enalapril alan hastaları içermektedir. Hatta hastaların ilacı geçici veya kalıcı bırakmalarına çalışma ekibini bilgilendirme şartı ile izin verilmiştir.
Sonuçta 3549 hastada doz azaltımına gidilmiştir (sakubitril/valsartan: $n=1755$, enalapril: $n=1794$ ). Sakubitril/valsartan alan kişiler arasında en sık doz azaltımına gidilmesinin nedeni hipotansiyon iken enalaprile randomize edilenlerde öksürük olmuştur. Sonrasında hedef doza geri dönme oranı sakubitril/ valsartan grubunda enalapril grubuna göre anlam11 olarak daha fazladir (sirasiyla \%39.8 ve \%35.5, $\mathrm{p}=0.005$ ).

Her iki ilaç için de herhangi bir sebeple doz azaltılması, tam doz alımına göre, kardiyovasküler ölüm veya hastaneye yatışdan oluşan primer olay riskinde artış ile ilişkili bulunmuştur (Şekil 1). Fakat bu olay artış1 enalapril gurubunda sakubitril/valsartan grubuna göre daha fazla olmuştur (Şekil 2). Sonuç olarak, her iki ilacın hedef dozla uygulandikları zamankine benzer oranda olmak üzere (HR 0.80, \%95 CI $0.70-0.93, \mathrm{p}<0.001)$, sakubitril/valsartan lehine olan klinik fayda devam etmiştir (HR 0.79, \%95 CI $0.71-0.88, \mathrm{p}<0.001)$.

Çok değişkenli analizde; ileri yaş, yüksek kalp hızı, düşük sistolik kan basıncı, böbrek yetersizliği ve KY evresinin ileri olması, her iki ilaç için de doz azaltılmasının öngördürücüleri olarak saptanmıştır. Amerika ve Avrupa'dan alınan hastalarda Asya'dan alınan hastalara göre daha fazla oranda doz azaltımına ihtiyaç duyulmuştur.

İlaçları tamamen bırakan hastalar değerlendirildiğinde ilk 30 günde Sakubitril/valsartan grubunda birincil sonlanım açısından fayda devam etmiştir. Ancak mortalite açısından iki grup arasında fark gözlenmemiştir.

Çalışma ilaçlarının kümülatif ortalama doz seviyesi incelendiğinde, daha düşük ortalama sakubitril/ valsartan dozları alanlarda, daha düşük enalapril dozları alan katılımcılara kıyasla daha az kardiyovasküler olay veya hastaneye yatış olmuştur (Şekil 3). 


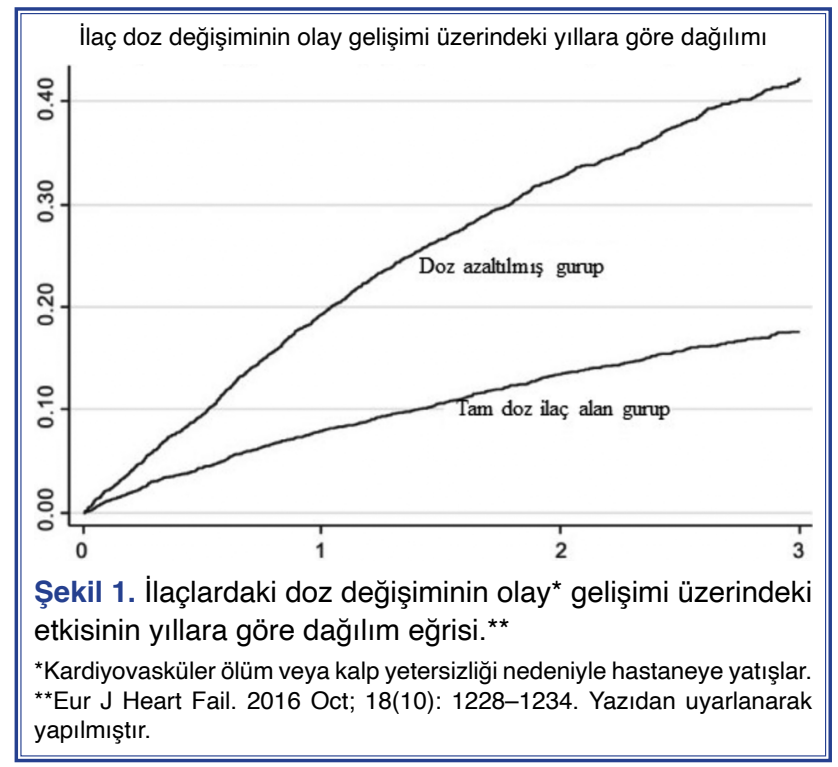

Çeşitli KY kayıtlarından elde edilen veriler, kılavuz önerilerine rağmen, hastaların ancak yarısından daha azının, hem anjiyotensin konverting enzim inhibitörleri hem de beta-blokerler için, hedef dozlarla tedavi edildiğini göstermektedir. ${ }^{[4]}$ MERIT-HF çalışmasında hedef doza ulaşamayan hastalarda, olay sıklığının arttığı ancak başarılı titrasyon uygulanan hastalara benzer şekilde tedaviden fayda gördükleri saptanmıştır. ${ }^{[5]}$ COMET çalışmasında karvedilol alan hastaların \% 75'inde, metoprolol alan hastaların \%78 inde hedef dozlara ulaşılabilmiştir. ${ }^{[6]}$ Hedef doza ulaşamama olay riskini arttırmıştır. Ancak karvedilolün metoprolola olan üstünlüğü devam etmiştir.

PARADIGM-HF çalışmasında da alıştırma periyoduna rağmen önemli oranda bir hastada doz azaltımına gidilmiştir. Hastaların kırılganlığı, hipotansiyon atakları, böbrek değerleri ilaçların maksimum dozda kullanımına izin vermemiştir. Bilindiği gibi bu doz azaltılmaları veya düşük dozda tedaviye devam edilmesi gerçek yaşam verilerinde daha fazladır. İngiltere' de yayınlanan gerçek yaşam verilerinde bu kanıtlanmış; yaşlı ve kırılganlığı yüksek hastalarda birçok ilacın yeterli doza çıkılamadı̆̆ gösterilmiştir. ${ }^{[7]}$

Sonuç olarak, PARADIGM-HF çalışmasındaki hastalarda hem sakubitril/valsartan hem de enalapril için doz azaltımıyla olay sıklığı artmıştır. Ancak, hedef dozun altındaki dozlarda da sakubitril/valsartanın enalaprile olan klinik üstünlüğü korunmuştur. Doz azaltılan grubun özellikleri incelendiğinde kardiyovasküler açıdan yüksek riskli ve tedaviden fayda görme olasılığı daha fazla olan hastalardır. Bu

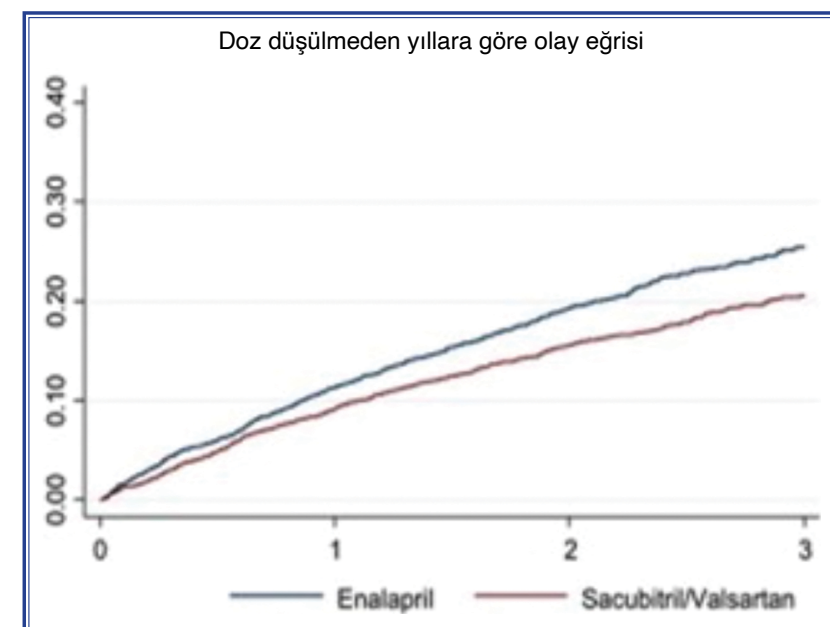

Doz azaldıktan sonra yıllara göre olay eğrisi

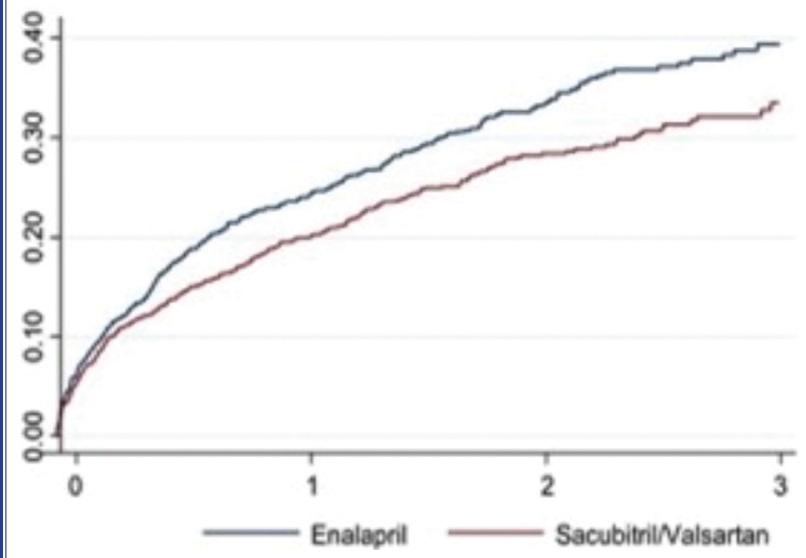

Şekil 2. İki gurup arasında doz değişiminin olay* gelişimi üzerindeki etkisinin yıllara göre dağılım. **

*Kardiyovasküler ölüm veya kalp yetersizliği nedeniyle hastaneye yatışlar. **Eur J Heart Fail. 2016 Oct; 18(10): 1228-1234. Yazıdan uyarlanarak yapılmıştır.

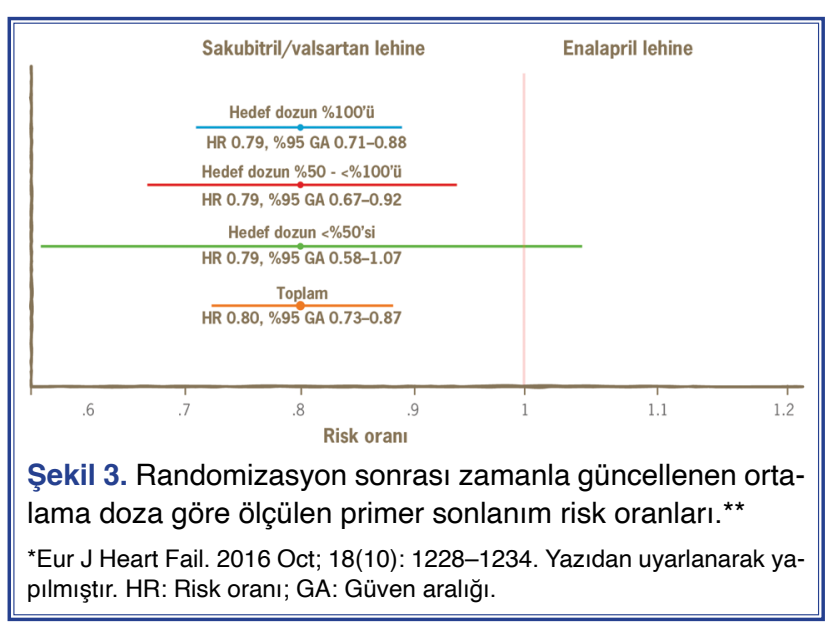

nedenle uygun titrasyon ile hastanın tolere edebildiği en yüksek dozda sakubitril/valsartan tedavisine devam edilmelidir. 


\section{Kaynaklar}

1. McMurray JJ, Packer M, Desai AS, Gong J, Lefkowitz MP, Rizkala $\mathrm{AR}$, et al. Angiotensin-neprilysin inhibition versus enalapril in heart failure. N Engl J Med 2014;371:993-1004.

2. Ponikowski P, Voors AA, Anker SD, Bueno H, Cleland JGF, Coats AJS, et al. 2016 ESC Guidelines for the diagnosis and treatment of acute and chronic heart failure: The Task Force for the diagnosis and treatment of acute and chronic heart failure of the European Society of Cardiology (ESC)Developed with the special contribution of the Heart Failure Association (HFA) of the ESC. Eur Heart J 2016;37:2129-200.

3. Vardeny O, Claggett B, Packer M, Zile MR, Rouleau J, Swedberg K, et al. Efficacy of sacubitril/valsartan vs. enalapril at lower than target doses in heart failure with reduced ejection fraction: the PARADIGMHF trial. Eur J Heart Fail 2016;18:1228-34.

4. Fonarow GC, Abraham WT, Albert NM, Stough WG, Gheorghiade
M, Greenberg BH, et al. Dosing of beta-blocker therapy before, during, and after hospitalization for heart failure (from Organized Program to Initiate Lifesaving Treatment in Hospitalized Patients with Heart Failure). Am J Cardiol 2008;102:1524-9.

5. Wikstrand J, Hjalmarson A, Waagstein F, Fagerberg B, Goldstein S, Kjekshus J, et al. Dose of metoprolol CR/XL and clinical outcomes in patients with heart failure: analysis of the experience in metoprolol $\mathrm{CR} / \mathrm{XL}$ randomized intervention trial in chronic heart failure (MERIT-HF). J Am Coll Cardiol 2002;40:491-8.

6. Metra M, Torp-Pedersen C, Swedberg K, Cleland JG, Di Lenarda A, Komajda M, et al. Influence of heart rate, blood pressure, and betablocker dose on outcome and the differences in outcome between carvedilol and metoprolol tartrate in patients with chronic heart failure: results from the COMET trial. Eur Heart J 2005;26:2259-68.

7. Calvert MJ, Shankar A, McManus RJ, Ryan R, Freemantle N. Evaluation of the management of heart failure in primary care. Fam Pract 2009;26:145-53. 